Online Submissions: http:/ / www.wjgnet.com/1007-9327office wjg@wjgnet.com

\title{
Patient interest in video recording of colonoscopy: A survey
}

\author{
Meghana Raghavendra, Douglas K Rex
}

Meghana Raghavendra, Douglas K Rex, Division of Gastroenterology/Hepatology, Indiana University Medical Center, Indianapolis, IN 46202, United States

Author contributions: Raghavendra M conducted the survey. Raghavendra M and Rex DK analyzed the data and wrote the manuscript.

Correspondence to: Douglas K Rex, MD, Department of Medicine, Division of Gastroenterology, Indiana University School of Medicine, 550 N. University Boulevard UH 4100, Indianapolis, IN 46202, United States. drex@iupui.edu Telephone: +1-317-2788741 Fax:+1-317-2745449

Received: July 21, 2009 Revised: August 18, 2009

Accepted: August 25, 2009

Published online: January 28, 2010

\section{Abstract}

AIM: To find if patients are interested in obtaining a video recording of their colonoscopy procedure.

METHODS: We conducted a survey of outpatients presenting for colonoscopy regarding their interest in obtaining a video recording of their colonoscopy.

RESULTS: Two hundred and forty-eight patients (mean age 57.9 years; $57 \%$ male) were surveyed. Two hundred and one patients (81\%) were interested in obtaining a video recording. No significant predictors of patients' interest in the video recording were identified. After reading a brief educational paragraph explaining missed lesions during colonoscopy, 135 patients (54\%) were more interested in having a video recording, and none were less interested. One hundred and fifty-six patients (63\%) were willing to pay for a video recording. In multivariable analyses, younger age was predictive of willingness to pay for a video recording. Prior history of colorectal cancer and a family history of colorectal cancer were predictive of willingness to pay a greater amount.

CONCLUSION: Patients undergoing colonoscopy expressed substantial interest in obtaining a videore- cording of their procedure. Awareness of missing lesions during colonoscopy increased interest in having a videorecording.

(c) 2010 Baishideng. All rights reserved.

Key words: Colonoscopy; Video recording; Survey

Peer reviewer: Dr. Shinji Tanaka, Director, Department of Endoscopy, Hiroshima University Hospital, 1-2-3 Kasumi, Minami-ku, Hiroshima 734-8551, Japan

Raghavendra M, Rex DK. Patient interest in video recording of colonoscopy: A survey. World J Gastroenterol 2010; 16(4): 458-461 Available from: URL: http://www.wjgnet. com/1007-9327/full/v16/i4/458.htm DOI: http://dx.doi. org/10.3748/wjg.v16.i4.458

\section{INTRODUCTION}

There is increasing awareness that colonoscopy fails to prevent a substantial fraction of colorectal cancers ${ }^{[1-8]}$ and that the performance of colonoscopy is highly operator dependent ${ }^{[9,10]}$. Some studies that have demonstrated imperfect protection ${ }^{[8]}$ and operator dependency ${ }^{[9]}$ have received considerable lay press attention. Recent studies have suggested that there is less protection against colorectal cancer by colonoscopy in the proximal compared to the distal colon ${ }^{[8,1]}$. Part of the cause of inadequate right colon protection might be exaggeration of cecal intubation rates by poorly trained colonoscopists ${ }^{[8]}$. Indeed, colonoscopies are often poorly documented with regard to cecal intubation, and reports claiming cecal intubation often fail to document cecal landmarks by notation or photography ${ }^{[12]}$.

We reasoned that as awareness of operator dependency of colonoscopy increases, some patients might be interested in obtaining a video recording of their colonoscopy, either as a way of ensuring that their examination was of high quality, or based on interest in viewing 
the procedure, because patients are often not able to watch the examination in real-time.

Therefore, we conducted a survey of patients undergoing colonoscopy at Indiana University Hospital as to their interest in obtaining a video recording of their procedure and their willingness to pay for the recording.

\section{MATERIALS AND METHODS}

The survey was conducted in 250 patients presenting to Indiana University Hospital or an ambulatory surgery center associated with the hospital. Permission to perform the survey was granted by the Institutional Review Board at Indiana University/Purdue University Indianapolis/Clarian Health Partners.

The survey identified age, gender, occupation, whether and how many prior colonoscopies the patient had undergone, any personal history of colorectal polyps or cancer, family history of colorectal cancer, and whether they owned a digital versatile disc (DVD) player. Patients were asked whether they would be interested in owning a video recording of their colonoscopy and were asked for an explanation of their response.

In the second part of the survey, there was a brief educational paragraph explaining miss rates during colonoscopy. Patients were asked if this explanation made them more or less likely to want a video recording. Patients were asked about their willingness to pay for the video recording and the amount they would pay. The paragraph read by the patients was as follows: "Colonoscopists have been shown to vary 4- to 10 -fold in the number of precancerous polyps they detect and remove during colonoscopy. This means that some colonoscopists miss more than half of the precancerous polyps in the colon. Does this information make you: (A) Less likely to want a digital recording of your colonoscopy? (B) More likely to want a digital recording of your colonoscopy? (C) No change in your decision for a digital recording of your colonoscopy".

The surveys were conducted by a physician trained in internal medicine. The study was considered exploratory and the sample size was arbitrary. Patients were consecutive to the extent that the survey administrator was available and not already occupied with conducting a survey.

Chi square tests and logistic regression were used to determine whether the survey items were significant predictors of the desire to have a video recording of the colonoscopy and of willingness to pay for the video recording. Two-sample $t$-tests and correlation coefficients were used to determine how much patients were willing to pay. The amounts were analyzed two ways: (A) using only those patients who answered they were willing to pay and (B) using all patients, with those who answered they were unwilling to pay recorded as willing to pay zero dollars. To examine multiple-variable models, a backward elimination procedure was used, with all variables individually significant at $P<0.30$ included initially, and then removing variables one at a time until only variables with $P$ values $<0.05$ remained.
Table 1 Patient interest in owning a DVD of their colonoscopy

\begin{tabular}{lcrcc}
\hline & & Interested & Not Interested & $\boldsymbol{P}$ \\
\hline Age in years, mean (SD) & & $57.8(12.8)$ & $58.7(12.8)$ & 0.66 \\
Gender & F & $90(85)^{1}$ & $16(15)^{1}$ & 0.21 \\
& M & $110(79)^{1}$ & $30(21)^{1}$ & \\
Own DVD player & Y & $193(81)^{1}$ & $44(19)^{1}$ & 0.78 \\
& N & $7(78)^{1}$ & $2(22)^{1}$ & \\
Prior Colonoscopy & Y & $151(83)^{1}$ & $31(17)^{1}$ & 0.28 \\
& N & $50(77)^{1}$ & $15(23)^{1}$ & \\
History of Polyps & Y & $100(82)^{1}$ & $22(18)^{1}$ & 0.81 \\
& N & $101(82)^{1}$ & $24(19)^{1}$ & \\
History of CRC & Y & $9(90)^{1}$ & $1(10)^{1}$ & 0.48 \\
& N & $192(81)^{1}$ & $45(19)^{1}$ & \\
FH of CRC & Y & $47(84)^{1}$ & $9(16)^{1}$ & 0.57 \\
& N & $153(81)^{1}$ & $37(19)^{1}$ & \\
\hline
\end{tabular}

SD: Standard deviation; F: Female; M: Male; Y: Yes; N: No; DVD: Digital video disc; FH: Family history; CRC: Colorectal cancer. ${ }^{1}$ Number (percent).

\section{RESULTS}

Two hundred and fifty patients were approached to answer the survey. One patient refused to participate and one was excluded due to inconsistent information. One patient did not answer whether they wanted a DVD, and a few data points were missing from other surveys (Tables 1 and 2). Thus, 248 patient surveys were available for analyses. Patients ranged in age from 19 to 87 years (mean 57.9 years). There were 238 patients $(96 \%)$ who owned DVD players. There were 141 (57\%) males, $183(74 \%)$ had undergone a prior colonoscopy, and $123(50 \%)$ had a prior history of polyps. Ten patients (4\%) had a personal history of colorectal cancer, while 57 (23\%) has a family history of colorectal cancer.

Among the 248 patients, 201 (81\%) were interested in obtaining a video recording of their colonoscopy. Among the factors age, gender, prior colonoscopy, polyp history, history of colorectal cancer, and family history of colorectal cancer, none of these predicted desire to have a video recording in univariate analyses. Multivariate analysis confirmed that none of the factors was associated with an interest in obtaining a video recording (Table 1$)$.

After a brief educational paragraph regarding polyp miss rates, interest in obtaining a video recording of colonoscopy was reassessed. One hundred thirty-five patients $(54 \%)$ were more interested in video recording and none were less interested.

The most common reason for interest in having a video recording was "review" (68 patients, $27 \%$ ), followed by "better records" (55 patients, 22\%) and "better information" (43 patients, 17\%) (Table 2). The most common reason for lack of interest in obtaining video recording was "no benefit over pictures" (Table 2).

There were 72 males $(68 \%)$ and 84 females $(60 \%)$ who stated they would be willing to pay for a video recording of their colonoscopy. A family history of colorectal cancer (odds ratio 2.09; 1.07-4.09) and younger age (odds ratio $1.39 ; 1.12-1.72$ for each 10 year interval of decreasing 


\begin{tabular}{|c|c|}
\hline \multicolumn{2}{|l|}{ Reasons for interest in videorecording } \\
\hline Review & $68(27)$ \\
\hline Better records & $55(22)$ \\
\hline $\begin{array}{l}\text { Better information (more data, better image, } \\
\text { better understanding) }\end{array}$ & $43(17)$ \\
\hline Comparison & $37(15)$ \\
\hline $\begin{array}{l}\text { Follow-up (includes baseline information, } \\
\text { follow changes, reference for next procedure) }\end{array}$ & $24(10)$ \\
\hline Research/educational tool & $16(6)$ \\
\hline Interesting & $11(4)$ \\
\hline Second opinion & $9(4)$ \\
\hline Medical-legal & $1(<1)$ \\
\hline Can take videorecording along if relocating & $2(1)$ \\
\hline \multicolumn{2}{|l|}{ Reasons for lack of interest in videorecording } \\
\hline No benefit over pictures, no benefit, not useful & $32(13)$ \\
\hline Don't see need, trust physician expertise & $7(3)$ \\
\hline No opinion & $3(1)$ \\
\hline
\end{tabular}

Table 3 Predictors of stated willingness to pay for a video recording (univariate analysis)

\begin{tabular}{lcrrrc}
\hline & \multicolumn{2}{c}{$\begin{array}{c}\text { Willing to } \\
\text { pay }\end{array}$} & $\begin{array}{c}\text { Not willing } \\
\text { to pay }\end{array}$ & $\boldsymbol{P}$ & $\begin{array}{c}\text { Odds ratio } \\
(\mathbf{9 5} \% \mathbf{C l})\end{array}$ \\
\hline Gender & $\mathrm{F}$ & $72(68)^{1}$ & $34(32)^{1}$ & 0.18 & $1.44(0.85,2.44)$ \\
& $\mathrm{M}$ & $84(60)$ & $57(40)$ & & \\
DVD player & Yes & $152(64)$ & $86(36)$ & 0.25 & $2.21(0.58,8.45)$ \\
& No & $4(44)$ & $5(56)$ & & \\
Prior & Yes & $116(63)$ & $67(37)$ & 0.96 & $1.01(0.56,1.82)$ \\
colonoscopy & No & $41(63)$ & $24(37)$ & & \\
History of & Yes & $72(59)$ & $51(41)$ & 0.12 & $0.66(0.4,1.12)$ \\
polyps & No & $85(68)$ & $40(32)$ & & \\
History of CRC & Yes & $9(90)$ & $1(10)$ & 0.11 & $5.47(0.68,43.92)$ \\
& No & $148(62)$ & $90(38)$ & & \\
FH of CRC & Yes & $43(75)$ & $14(25)$ & 0.03 & $2.09(1.07,4.09)$ \\
& No & $113(59)$ & $77(41)$ & & \\
Age, mean (SD) & & $55.9(12.7)$ & $61.4(13.9)$ & 0.002 & $1.39(1.12-1.72)^{2}$ \\
\hline
\end{tabular}

${ }^{1}$ Number of patients (\%); ${ }^{2}$ Odds ratio for a 10 -year decrease in age.

age) predicted willingness to pay for a video recording in univariate analyses (Table 3 ). In a multivariable analysis using a backward elimination procedure to remove nonsignificant factors, only younger age remained in the model, with a $P$ value of 0.002 .

With regard to the amount patients were willing to pay, univariate analyses showed that a prior history of colorectal cancer was the only predictor of willingness to pay more (mean $\$ 354$ vs $\$ 65, P=0.001$ ), if only those willing to pay were considered (Table 4). If patients who were unwilling to pay for a video recording were assigned an amount of zero dollars, so that all patients interested in having a video recording were included, a prior history of colorectal cancer was the only predictor of the amount patients were willing to pay ( $\$ 319$ vs $\$ 40, P=0.0001$ ), though female gender approached significance ( $\$ 76$ vs $\$ 33, P=0.06$ ) (Table 4). In multivariable analysis, prior colorectal cancer $(P=$ $0.0003)$ and a family history of colorectal cancer $(P=$ $0.02)$ were both predictive of a higher amounts patients
Table 4 Amounts patients were willing to pay for a video recording (univariate analysis)

\begin{tabular}{|c|c|c|c|c|c|}
\hline & & \multicolumn{2}{|c|}{$\begin{array}{l}\text { Amount willing to pay, } \\
\text { considering only those } \\
\text { willing to pay }\end{array}$} & \multicolumn{2}{|c|}{$\begin{array}{l}\text { Amount willing to pay, } \\
\text { considering all patients }\end{array}$} \\
\hline & & mean $(\$)(S D)$ & $\boldsymbol{P}$ & mean $(\$)(S D)$ & $P$ \\
\hline \multirow[t]{2}{*}{ Gender } & $\mathrm{F}$ & $112.2(288.7)$ & 0.11 & $76.2(243.2)$ & 0.06 \\
\hline & $\mathrm{M}$ & 55.4 (128.2) & & $32.9(102.2)$ & \\
\hline \multirow[t]{2}{*}{ DVD player } & Yes & $83.4(221.8)$ & 0.63 & $53.1(181.3)$ & 0.51 \\
\hline & No & 30 (13.5) & & $13.3(17.9)$ & \\
\hline \multirow{2}{*}{$\begin{array}{l}\text { Prior } \\
\text { colonoscopy }\end{array}$} & Yes & $89.2(249.4)$ & 0.46 & $56.5(202.8)$ & 0.46 \\
\hline & No & $59.6(74.6)$ & & $37.3(65.5)$ & \\
\hline \multirow{2}{*}{$\begin{array}{l}\text { History of } \\
\text { polyps }\end{array}$} & Yes & $90.3(270.1)$ & 0.65 & $52.6(210.3)$ & 0.93 \\
\hline & No & 74.3 (164.6) & & 50.5 (139.9) & \\
\hline \multirow{2}{*}{$\begin{array}{l}\text { History of } \\
\text { CRC }\end{array}$} & Yes & 353.9 (634.6) & 0.001 & 318.5 (608.7) & 0.0001 \\
\hline & No & $64.9(154)$ & & 40.3 (125.2) & \\
\hline \multirow[t]{2}{*}{ FH of CRC } & Yes & $92.3(177.1)$ & 0.72 & $69.6(158.5)$ & 0.39 \\
\hline & No & 78.2 (233.7) & & $46.3(183.7)$ & \\
\hline \multirow[t]{2}{*}{ Age } & & Correlation & $P$ & Correlation & $P$ \\
\hline & & 0.07 & 0.40 & 0.01 & 0.92 \\
\hline
\end{tabular}

EGC: EGD and colonoscopy.

were willing to pay, considering only those willing to pay. When all subjects were included, prior colorectal cancer $(P=0.0002)$ and a family history of colorectal cancer $(P$ $=0.001$ ) remained predictive of amount willing to pay for a video recording.

\section{DISCUSSION}

In this study, we report interest among outpatients presenting to Indiana University Hospital and an ambulatory surgery center operated by our gastroenterology group, in obtaining a video recording of their colonoscopy. In our study, of the 248 patient surveys included, the majority (81\%) were interested in having a video recording.

Sixty-three percent of patients said they were willing to pay for a video recording of their colonoscopy. Payment by patients could offset the costs of video recording. We found no significant predictors of desire to have a video recording, but a family history of colorectal cancer and younger patients' age predicted willingness to pay for a video recording.

Following the educational paragraph on missed lesions during colonoscopy, $54 \%$ of patients showed an increased interest in a video recording. Thus, increasing awareness of imperfect detection by colonoscopy increases interest in video recordings.

While video recordings can differentiate the quality of an individual colonoscopist's examination technique and time ${ }^{[13,14]}$, they are seldom obtained routinely during clinical practice. The impact of simply performing video recording during colonoscopy on quality and medicallegal risk is unknown.

A primary limitation of the study is that we did not actually test willingness to pay for video recordings by offering them for sale. Anecdotally, video recordings 
of colonoscopies are rarely made available to patients routinely in the United States, either with or without payment by patients. Our gastroenterology group has not yet decided whether to pursue sale of video recordings as routine practice or to make systematic video recordings for inclusion in medical records. We found that younger age predicted stated willingness to pay for a video recording, and prior colorectal cancer and a family history of colorectal cancer predicted willingness to pay greater amounts.

In summary, a survey of 248 patients undergoing colonoscopy was conducted. The majority expressed interest in obtaining a video recording of their procedure. Awareness of missed lesions during colonoscopy increased patient interest in having a video recording. While there were no predictors of interest in having a video recording, younger patients were more willing to pay for a video recording. Prior colorectal cancer and family history of colorectal cancer predicted willingness to pay more for a video recording. We conclude that patient interest in having a video recording of their colonoscopy is substantial, and that awareness of missed lesions during colonoscopy increases interest in having a video recording. Payment by patients for video recordings is a potential mechanism of offsetting the cost of making video recordings.

\section{COMMENTS}

\section{Background}

Colonoscopy is operator-dependent and substantial numbers of pre-cancerous polyps are missed during colonoscopy. Colonoscopies are often poorly documented, with only a few still photographs taken of anatomic landmarks and abnormal findings.

\section{Research frontiers}

Video recording is rarely used in colonoscopy except for teaching purposes; therefore, the potential impact of systematic video recording on the quality of colonoscopy us unknown. In this study the authors sought to understand patient interest in obtaining video recordings of their colonoscopies, and their willingness to pay for video recordings.

\section{Innovations and breakthroughs}

No previous investigation of this issue has been made. Therefore the whole field of video recording of colonoscopies with regard to its effect on quality and cost, and medical-legal implications, is in its infancy.

\section{Applications}

These results indicate that $81 \%$ of patients have interest in obtaining video recordings of their colonoscopy, and for a variety of reasons. Information regarding missing lesions during colonoscopy increases interest. There is some willingness to pay for the video recording, which could in the future help to cover the costs of systematic video recording.

\section{Terminology}

Presently, colonoscopy is typically documented by still photography. Video recording in this paper refers to recording the entire colonoscopy or the withdrawal portion of the examination, and preserving the recording as a permanent record. Systematic digital recording of colonoscopy is becoming increasingly feasible.

\section{Peer review}

The authors conducted a survey of outpatients presenting for colonoscopy of their interest in obtaining a video recording of their colonoscopy. In my opinion, this paper is interesting.

\section{REFERENCES}

1 Alberts DS, Martínez ME, Roe DJ, Guillén-Rodríguez JM, Marshall JR, van Leeuwen JB, Reid ME, Ritenbaugh C, Vargas PA, Bhattacharyya AB, Earnest DL, Sampliner RE. Lack of effect of a high-fiber cereal supplement on the recurrence of colorectal adenomas. Phoenix Colon Cancer Prevention Physicians' Network. N Engl J Med 2000; 342: 1156-1162

2 Schatzkin A, Lanza E, Corle D, Lance P, Iber F, Caan B, Shike M, Weissfeld J, Burt R, Cooper MR, Kikendall JW, Cahill J. Lack of effect of a low-fat, high-fiber diet on the recurrence of colorectal adenomas. Polyp Prevention Trial Study Group. N Engl J Med 2000; 342: 1149-1155

3 Robertson DJ, Greenberg ER, Beach M, Sandler RS, Ahnen D, Haile RW, Burke CA, Snover DC, Bresalier RS, McKeown-Eyssen G, Mandel JS, Bond JH, Van Stolk RU, Summers RW, Rothstein R, Church TR, Cole BF, Byers T, Mott L, Baron JA. Colorectal cancer in patients under close colonoscopic surveillance. Gastroenterology 2005; 129: 34-41

4 Singh H, Turner D, Xue L, Targownik LE, Bernstein CN. Risk of developing colorectal cancer following a negative colonoscopy examination: evidence for a 10-year interval between colonoscopies. JAMA 2006; 295: 2366-2373

5 Rex DK, Rahmani EY, Haseman JH, Lemmel GT, Kaster S, Buckley JS. Relative sensitivity of colonoscopy and barium enema for detection of colorectal cancer in clinical practice. Gastroenterology 1997; 112: 17-23

6 Bressler B, Paszat LF, Chen Z, Rothwell DM, Vinden C, Rabeneck L. Rates of new or missed colorectal cancers after colonoscopy and their risk factors: a population-based analysis. Gastroenterology 2007; 132: 96-102

7 Singh $\mathbf{H}$, Turner D, Xue L, Targownik LE, Bernstein CN. Colorectal cancers after a negative colonoscopy. Gastroenterology 2007; 132: A149

8 Baxter NN, Goldwasser MA, Paszat LF, Saskin R, Urbach DR, Rabeneck L. Association of colonoscopy and death from colorectal cancer. Ann Intern Med 2009; 150: 1-8

9 Barclay RL, Vicari JJ, Doughty AS, Johanson JF, Greenlaw RL. Colonoscopic withdrawal times and adenoma detection during screening colonoscopy. $N$ Engl J Med 2006; 355: 2533-2541

10 Chen SC, Rex DK. Endoscopist can be more powerful than age and male gender in predicting adenoma detection at colonoscopy. Am J Gastroenterol 2007; 102: 856-861

11 Singh G, Gerson LB, Wang H, Nannalithara A, Mithal A, Graham DJ, Triadafilpous G. Screening colonoscopy, colorectal cancer and gender: An unfair deal for the fair sex? Gastrointest Endosc 2007; 65: AB100

12 Aslinia F, Uradomo L, Steele A, Greenwald BD, Raufman JP. Quality assessment of colonoscopic cecal intubation: an analysis of 6 years of continuous practice at a university hospital. Am J Gastroenterol 2006; 101: 721-731

13 Rex DK. Colonoscopic withdrawal technique is associated with adenoma miss rates. Gastrointest Endosc 2000; 51: 33-36

14 Thomas-Gibson S, Rogers PA, Suzuki N, Vance ME, Rutter MD, Swain D, Nicholls AJ, Saunders BP, Atkin W. Development of a video assessment scoring method to determine the accuracy of endoscopist performance at screening flexible sigmoidoscopy. Endoscopy 2006; 38: 218-225

S- Editor Tian L L- Editor Stewart GJ E- Editor Ma WH 